\section{(2) OPEN ACCESS}

\title{
Variability and predictors of weekly pesticide exposure in applicators from organic, sustainable and conventional smallholder farms in Costa Rica
}

\author{
Samuel Fuhrimann (1) , Philipp Staudacher 주, 2,3,4,5 Christian Lindh 두, ${ }^{6}$

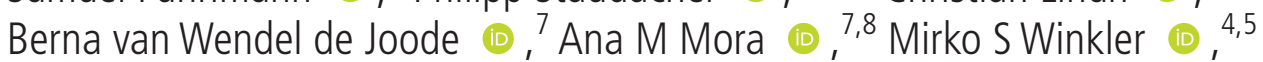 \\ Hans Kromhout (1) ${ }^{1}$
}

\begin{abstract}
- Additional material is published online only. To view please visit the journal online (http://dx.doi.org/10.1136/ oemed-2019-105884).
\end{abstract}

For numbered affiliations see end of article.

\section{Correspondence to} Dr Samuel Fuhrimann, Institute for Risk Assessment Sciences, Utrecht University, Utrecht 3512 JE, The Netherlands; s.fuhrimann@uu.nl

Received 30 May 2019 Revised 13 September 2019 Accepted 30 September 2019 Published Online First 2 December 2019

\section{Check for updates}

(c) Author(s) (or their employer(s)) 2020. Re-use permitted under CC BY-NC. No commercial re-use. See rights and permissions. Published by BMJ.

To cite: Fuhrimann $S$, Staudacher $\mathrm{P}$, Lindh $\mathrm{C}$, et al. Occup Environ Med 2020;77:40-47.

\section{ABSTRACT}

Objective Estimates of pesticide exposure among applicators from low- and middle-income countries (LMICs) are scarce, and exposure assessment methods are sometimes costly or logistically unfeasible. We examined the variability in weeklong pesticide exposure among applicators in Costa Rica and its predictors. Methods We conducted a cross-sectional survey among 221 pesticide applicators from organic, sustainable and conventional farms in 2016. We administered structured questionnaires to assess pesticide application practices at two time points (4-6 weeks apart). We adapted an existing algorithm to fit the context of smallholders and derive weekly pesticide exposure scores. We used linear mixed-effect models to examine within-worker and between-worker score variability. We then identified sociodemographic and occupational predictors of weekly pesticide exposure scores.

Results We observed high within-worker and betweenworker variability in weekly pesticide exposures (eg, up to 180-fold and 70-fold differences in average weekly exposures within and between workers, respectively; intraclass correlation coefficient $=0.4)$. Applicators working on conventional and sustainable farms had exposure scores twofold and 1.5-fold higher than those working in organic farms, respectively. Farm workers who received training on pesticide use had weekly pesticide exposure scores of 33\% (95\% Cl 1\% to 55\%) lower than those who did not receive any training.

Conclusions In this study of applicators from smallholder farms in Costa Rica, we determined the importance of collecting questionnaire data on selfreported pesticide use repeatedly due to its high variability within workers and absence of application records. Our questionnaire-based exposure algorithm could allow the calculation of semiquantitative estimates of average pesticide exposure for applicators from other LMICs.

\section{INTRODUCTION}

Quantification of occupational exposure to pesticides is crucial to investigate potential adverse health effects in workers. ${ }^{12}$ As it is often logistically not feasible or too costly to collect human samples (eg, urine, stool) and measure exposure biomarkers over time, algorithms have been developed to

\section{Key messages}

What is already known about this subject?

- Pesticide use in low- and middle-income countries (LMICs) is increasing, while there is a concern about safe application practices.

- Existing pesticide exposure assessments lack application-specific and context-specific understanding of the different agricultural settings in LMICs.

What are the new findings?

- We adapted an exposure algorithm developed for large-scale farms in a high-income country setting to fit the context of pesticide applications in smallholder farms in Costa Rica.

- We found that workers from conventional farms or who had not received training on pesticide use had the highest pesticide exposure scores.

- We observed high temporal variability in pesticide exposure scores within and between pesticide applicators.

How might this impact on policy or clinical practice in the foreseeable future?

- Accurate exposure assessment is of paramount public health importance given the extensive agricultural use of pesticides in LMICs.

- The modified exposure algorithm allows to assess the health effects of exposure to pesticides among applicators from LMICs.

calculate pesticide exposure intensity scores. ${ }^{3} 4$ These scores have been frequently estimated using self-reported data from questionnaires ${ }^{35-7}$ or observational checklists ${ }^{4} 9$ on pesticide formulation and exposure-modifying factors, such as use of personal protective equipment (PPE) and hygienic behaviours (eg, washing or changing clothes after an application). Exposure intensity scores have been developed for different farming systems around the world and have been successfully used to examine associations with multiple health outcomes, including neurobehaviour, ${ }^{10} 11$ diabetes, ${ }^{12}$ rhinitis, ${ }^{13}$ respiratory outcomes ${ }^{14}$ and cancer. ${ }^{15} 16$

Existing questionnaire-based pesticide exposure algorithms often lack validation and contextspecific understanding of different agricultural 
settings in low- and middle-income countries (LMICs). ${ }^{7}$ Most of these algorithms were developed for agricultural systems in high-income and cold-weathered countries in which pesticide applicators are trained on safe pesticide use and wear adequate PPE to minimise exposure. ${ }^{57}$ In addition, exposuremodifying factors included in these algorithms (eg, use of specialised PPE, frequency of PPE change, use of enclosed tanks) are frequently different for workers from small-sized and medium-sized farms, as these workers often apply pesticide using uncalibrated, basic spraying equipment, and use no or little PPE. ${ }^{17-19}$ Although some observation-based pesticide exposure algorithms such as the Dermal Exposure Assessment Method (DREAM) and the Determinants of Dermal Exposure Ranking Method have been used in LMICs, ${ }^{90-22}$ these may not be logistically feasible when studying large populations, when populations are scattered over a large area or when exposures are assessed repeatedly. ${ }^{22}$

Several factors can result in inaccurate or biased estimates of pesticide exposure for applicators from smallholder farms (farms $<20$ hectares that operate as family businesses and use mainly family labour ${ }^{23}$ ) in LMICs, including recall bias (as data on pesticide use often depend on self-reported use with limited accuracy of the amount and frequency of pesticide applications ${ }^{72425}$ ) and high between-farm and within-farm variability in pesticide applications. ${ }^{26}$ The lack of accurate pesticide exposure estimates is worrisome, particularly because agricultural production is on the rise in many LMICs, leading to an expanding workforce with unquantified exposure to hazardous pesticides ${ }^{27}$; this may also result in an increase in a wide range of undetected occupational and public health risks. ${ }^{1428}$

To address some of the above-mentioned shortcomings, this paper showcases an adapted questionnaire-based exposure algorithm to estimate weekly pesticide exposure scores for pesticide applicators in LMICs. ${ }^{57}$ More specifically, in the present study, we aimed to (1) examine the individual and temporal variability in weekly pesticide exposure among applicators; and (2) identify sociodemographic and occupational factors associated with weekly pesticide exposure estimates.

\section{METHODS}

\section{Study area and design}

This study is nested in the Pesticide Use in Tropical Settings (PESTROP) project, which aims to deepen the understanding of the environmental, health and regulatory dimensions of agricultural pesticide use in Costa Rica and Uganda. ${ }^{29}$ In Costa Rica, the project was conducted in Zarcero County and more specifically in the Tapezco river catchment area, which features approximately 760 smallholder farms with conventional, sustainable and organic practices. ${ }^{30}$ Common crops in the area include potatoes, tomatoes, cabbage, carrots and onions.

Detailed methods for the PESTROP project have been described elsewhere. ${ }^{29} 31$ Briefly, between June and September 2016 (season during which pesticide applications intensify due to increased rain $^{18}$ ), we enrolled 300 workers from 90 farms $(9$ organic, 19 sustainable and 62 conventional farms; between 1 and 18 workers per farm). Farms were classified based on pesticide use patterns described by the farm owners at enrolment:

- Conventional (unrestricted use of synthetic pesticides).

- Sustainable (controlled use of synthetic pesticides and trained on good agricultural practices).

- Organic (most certified as organic, some with limited use of synthetic pesticides, but all implemented biological pest management strategies ${ }^{17}$ ).
Eligible participants for the PESTROP project were farm owners, permanent workers or temporary pesticide applicators, all aged $\geq 18$ years, who owned or worked in conventional or sustainable farms located in the Tapezco river catchment or in organic farms within or near the catchment area, and who did not have a diagnosis of psychiatric disease or used psychopharmacological medications. Participants were visited twice (ie, baseline and follow-up visit) during the study duration, either at the farms where they worked or at their homes. Follow-up visits took place between 4 and 6 weeks after the baseline visit to allow for differences in pesticide use over time. ${ }^{32}$

In the present study, we included 221 (74\%) PESTROP participants who reported currently handling or using pesticides (ie, during the 12 months prior to the baseline or between the baseline and the follow-up visit), participated in both study visits and had complete data on exposure-modifying factors (see online supplementary figure S2).

\section{Interviews}

At the baseline visit, we collected information on sociodemographic characteristics, work history, training received on pesticide use (irrespective of the farming practice) and pesticide use (including the 15 pesticide active ingredients most commonly used in the study area; see online supplementary table S1) ${ }^{18}$ during the 12 months and 1 week prior to the study visit. Detailed data on total hours of pesticide use, frequency of PPE use and hygienic behaviours after pesticide use (ie, changing clothes and showering) were also collected. At the follow-up visit, we collected data on frequency and duration of pesticide applications and type of PPE used since the baseline visit (time between visits ranged between 4 and 6 weeks) and again during the 1 week prior to this visit.

\section{Pesticide exposure algorithm}

\section{Weekly pesticide exposure scores (EXPOSURE ${ }^{\text {WEEK}}$ )}

We adapted a questionnaire-based, deterministic, semiquantitative algorithm ${ }^{5}$ to estimate cumulative weekly pesticide exposure (EXPOSURE ${ }^{\text {WEEK }}$; equation 1) for two separate weeks (ie, weeks prior to study visits; table 1 ). The exposure score EXPOSURE ${ }^{\text {WEEK }}$ in weighted hours per week was estimated by multiplying an exposure intensity score (EXPOSURE $E^{\text {INTENSITY }}$; equation 2) and the total duration of any pesticide spraying during the week prior to the study visit.

EXPOSURE $^{\text {WEEK }}=$ EXPOSURE ${ }^{\text {INTENSITY }}$

$\times$ duration of pesticide spraying during last week (hours)

\section{Exposure intensity score (EXPOSURE ${ }^{\text {INTENSITY }}$ )}

The EXPOSURE ${ }^{I N T E N S I T Y}$ score (range: 0-13) was estimated based on a reduced and context-adapted set of five exposure-modifying factors used in previous algorithms (equation 2; table 1). ${ }^{57}$ Two factors were expected to increase pesticide exposure: (1) mixing of pesticides more than $75 \%$ of the time (MIX; score $\left.5^{7}\right)$; and (2) applying pesticides outdoors using manual handheld knapsack sprayers (APPLICATION; score $8^{7}$ ). Three factors were expected to decrease the exposure: (1) overall average protection achieved by PPE use (PPE; equation 3); (2) time interval between pesticide application and changing clothes (CHANGE; score $\left.0.7-1^{4}\right)$; and (3) time interval between application and showering (SHOWER; score $\left.0.7-1^{4}\right)$.

$$
\begin{aligned}
\text { EXPOSURE }^{\text {INTENSITY }=} & (\text { MIX }+ \text { APPLICATION }) \times \text { PPE } \\
& \times \text { CHANGE } \times \text { SHOWER }
\end{aligned}
$$


Table 1 Exposure-modifying factors used in the pesticide exposure algorithm

\begin{tabular}{|c|c|c|c|c|c|c|}
\hline Variable & Exposure-modifying factors & Exposure direction & Exposure route & Exposed/protected body area & $\begin{array}{l}\text { Deterministic } \\
\text { exposure scores }\end{array}$ & References \\
\hline MIX & $\begin{array}{l}\text { Mixing of pesticide formulation(s) with } \\
\text { water }\end{array}$ & Increase & Whole body & $\begin{array}{l}\text { Increase in exposure if mixing } \\
\text { pesticides }\end{array}$ & 5 & 6 \\
\hline APPLICATION & Manual handheld knapsack sprayers & Increase & Whole body & $\begin{array}{l}\text { Increase in exposure if applying } \\
\text { pesticides }\end{array}$ & 8 & 6 \\
\hline$P P E$ & Personal protective equipment (PPE) & Decrease & \multicolumn{2}{|c|}{$\begin{array}{l}\text { Used during pesticide handling: application and } \\
\text { mixing }\end{array}$} & 1 to 0.14 & Table 2 \\
\hline CHANGE & Changing clothes after application & Decrease & \multicolumn{2}{|c|}{$\begin{array}{l}\text { Next day, many hours later, few hours later, } \\
\text { immediately }\end{array}$} & $1,0.9,0.8,0.7$ & 3 \\
\hline SHOWER & Showering after application & Decrease & \multicolumn{2}{|c|}{$\begin{array}{l}\text { Next day, many hours later, few hours later, } \\
\text { immediately }\end{array}$} & $1,0.9,0.8,0.7$ & 3 \\
\hline
\end{tabular}

\section{PPE score}

The overall reduction of exposure intensity through PPE was estimated while taking into account the different inhalation and dermal exposure pathways ${ }^{4}$ (table 2 ; equation 3 ). Based on previous literature, hands were identified as the body part that was the most exposed during pesticide preparation and application (PPE ${ }^{H A N D}$; score 0.4 ; table 2 ; equation 3$),{ }^{5}$ followed by the upper body (due to the larger surface area compared with other body parts; $P P E^{U P-B O D Y}$; score 0.2$) .{ }^{4}$ Eyes, mouth, and legs and feet were considered to be similarly exposed (score of 0.1 ). ${ }^{5}$ Effectiveness of PPE was considered to be dependent on the quality of the equipment material (woven (0.3) and non-woven permeable $\left.(0.1)^{4}\right)$.

We classified the time that the applicator reported using his/ her PPE as follows: always (effect of protection over the entire pesticide handling time), often (25\% of the pesticide handling time without protection), sometimes $(50 \%$ of the pesticide handling time without protection), rarely ( $75 \%$ of the pesticide handling without protection) or never (no spraying protection at all). An average PPE score was estimated as follows:

$$
\begin{aligned}
P P E= & P P E^{U P-B O D Y}+P P E^{E Y E}+P P E^{M O U T H} \\
& +P P E^{H A N D}+P P E^{L E G}+P P E^{F E E T}
\end{aligned}
$$

In our estimations, we took into account (1) the exact values for the different PPE use situations (table 2); (2) that if two PPE were reported to had been used for the same body part, we selected the PPE with the highest protection factor; (3) that wearing a kimono or overall protected the upper body
$\left(P P E^{U P-B O D Y}\right)$ and legs $\left(P P E^{L E G}\right)$; and (4) that wearing a hat was considered to only marginally add to the protection and hence was left out.

\section{Example of pesticide exposure score estimation}

A pesticide applicator reported that he was both mixing and applying pesticides. He said that he changed his work clothes immediately after application but showered many hours later. He used gloves most of the time, boots always, an overall always and a mask with carbon filter sometimes; he never used glasses. During the week prior to the baseline visit, he applied pesticides for 12 hours. Hence, the applicator would have an EXPOSUREWEEK score of 24.96 .

$$
\begin{aligned}
& P P E=0.06 P P E^{U P-B O D Y}+0.1 P P E^{E Y E}+0.01 P P E^{M O U T H}+ \\
& 0.16 P P E^{H A N D}+0.03 P P E^{L E G}+0.01 P P E^{F E E T}=0.25 \\
& \text { EXPOSURE }^{\text {INTENSITY }}=(5 \mathrm{MIX}+8 \text { APPLICATION }) \times 0.25 \\
& P P E \times 0.7 \text { CHANGE } \times 0.9 \text { SHOWER }=2.08 \\
& \text { EXPOSURE }^{\text {WEEK }}=2.08 \text { EXPOSURE }{ }^{I N T E N S I T Y} \times 12 \text { duration of pesticide } \\
& \text { spraying during last week (hours) }=24.96
\end{aligned}
$$

\begin{tabular}{|c|c|c|c|c|c|c|c|c|c|c|}
\hline \multirow{2}{*}{$\begin{array}{l}\text { Exposure pathway } \\
\text { Body area }\end{array}$} & \multirow{2}{*}{$\begin{array}{l}\text { Inhalation } \\
P P E^{\text {MOUTH }}\end{array}$} & & \multicolumn{7}{|c|}{ Dermal exposure } & \multirow{2}{*}{$\begin{array}{l}\text { Whole body } \\
P P E\end{array}$} \\
\hline & & & $P P E^{\mathrm{EYE}}$ & $P P E^{\text {HAND }}$ & $P P E^{U P-B O D Y}$ & & $P P E^{\mathrm{LEG}}$ & & $P P E^{\mathrm{FEET}}$ & \\
\hline Relative contribution & 0.1 & & 0.1 & 0.4 & 0.2 & & 0.1 & & 0.1 & 1 \\
\hline PPE items & Dust mask & $\begin{array}{l}\text { Mask with } \\
\text { carbon filter }\end{array}$ & Goggles & Gloves & $\begin{array}{l}\text { Overall or } \\
\text { long-sleeve } \\
\text { shirt }\end{array}$ & $\begin{array}{l}\text { Rubber apron } \\
\text { or } \\
\text { rain poncho }\end{array}$ & $\begin{array}{l}\text { Overall or } \\
\text { long pants }\end{array}$ & $\begin{array}{l}\text { Gaiters or } \\
\text { waterproof } \\
\text { pants }\end{array}$ & Rubber boots & $\begin{array}{l}\text { Cumulative } \\
\text { effect over al } \\
\text { PPE }\end{array}$ \\
\hline PPE quality & W & NWP & NWP & W or NWP & W & NWP & W & NWP & NWP & \\
\hline \multicolumn{11}{|c|}{ Exposure reduction when using PPE } \\
\hline All the time $(100 \%)$ & 0.30 & 0.10 & 0.10 & 0.20 & 0.30 & 0.10 & 0.30 & 0.10 & 0.10 & \\
\hline $\begin{array}{l}\text { Most of the time } \\
(75 \%)\end{array}$ & 0.48 & 0.33 & 0.33 & 0.40 & 0.48 & 0.33 & 0.48 & 0.33 & 0.33 & \\
\hline Often $(50 \%)$ & 0.65 & 0.55 & 0.55 & 0.60 & 0.65 & 0.55 & 0.65 & 0.55 & 0.55 & \\
\hline Rarely & 0.83 & 0.78 & 0.78 & 0.80 & 0.83 & 0.78 & 0.83 & 0.78 & 0.78 & \\
\hline Never & 1.00 & 1.00 & 1.00 & 1.00 & 1.00 & 1.00 & 1.00 & 1.00 & 1.00 & \\
\hline $\begin{array}{l}\text { Actual exposure: } \\
\text { example for best } \\
\text { possible protection }\end{array}$ & 0.03 & 0.01 & 0.01 & 0.08 & 0.06 & 0.02 & 0.03 & 0.01 & 0.01 & 0.14 \\
\hline
\end{tabular}

\section{Statistical analyses}

First, we examined the association between exposure intensity scores at the baseline and follow-up visits using Pearson correlation coefficients. Second, we identified two different data sets:

NWP, non-woven permeable; PPE, personal protective equipment; W, woven PPE. 
Table 3 Sociodemographic and occupational characteristics of pesticide applicators, Zarcero County, Costa Rica, 2016

\begin{tabular}{|c|c|c|c|c|}
\hline & All & Organic & Sustainable & Conventional \\
\hline Farmers' characteristics, n (\%) & $221(100)$ & $19(13.3)$ & $62(26.9)$ & $140(59.9)$ \\
\hline \multicolumn{5}{|l|}{ Sex } \\
\hline Male & $219(99.1)$ & $19(100)$ & $61(98.4)$ & $139(99.3)$ \\
\hline Female & $2(0.9)$ & $0(0)$ & $1(1.6)$ & $1(0.7)$ \\
\hline \multicolumn{5}{|l|}{ Age (years) } \\
\hline $18-24$ & $55(24.9)$ & $6(31.6)$ & $15(24.2)$ & $34(24.3)$ \\
\hline $25-39$ & 79 (35.7) & $9(47.4)$ & $26(41.9)$ & $44(31.4)$ \\
\hline $40+$ & $87(39.4)$ & $4(21.1)$ & $21(33.9)$ & $62(44.3)$ \\
\hline \multicolumn{5}{|l|}{ Education } \\
\hline Sixth grade and under & $153(69.2)$ & $10(52.6)$ & $42(67.7)$ & $101(72.1)$ \\
\hline Seventh to eleventh grade & $42(19.0)$ & $5(26.3)$ & $11(17.7)$ & $26(18.6)$ \\
\hline Finished high school & $26(11.8)$ & $4(21.1)$ & $9(14.5)$ & $13(9.3)$ \\
\hline \multicolumn{5}{|l|}{ Country of birth } \\
\hline Costa Rica & $135(61.1)$ & $11(57.9)$ & $35(56.5)$ & $89(63.6)$ \\
\hline Nicaragua & $86(38.9)$ & $8(42.1)$ & $27(43.5)$ & $51(36.4)$ \\
\hline \multicolumn{5}{|l|}{ Household income* } \\
\hline Above poverty line & $139(62.9)$ & $15(78.9)$ & $36(58.1)$ & $88(62.9)$ \\
\hline Below poverty line & $67(30.3)$ & $4(21.1)$ & $20(32.3)$ & $43(30.7)$ \\
\hline \multicolumn{5}{|l|}{ Job category } \\
\hline Worker & $125(56.6)$ & $11(57.9)$ & $38(61.3)$ & $76(54.3)$ \\
\hline Owner & $96(43.4)$ & $8(42.1)$ & $24(38.7)$ & $64(45.7)$ \\
\hline \multicolumn{5}{|l|}{ Training on pesticide application } \\
\hline Yes & $110(49.8)$ & $15(78.9)$ & $24(38.7)$ & $71(50.7)$ \\
\hline \multicolumn{5}{|l|}{ Mixing of pesticide formulations } \\
\hline Yes & $177(80.1)$ & $13(68.4)$ & $47(75.8)$ & $117(83.6)$ \\
\hline \multicolumn{5}{|l|}{ Applied pesticides during week before } \\
\hline Baseline visit & $173(78.3)$ & $12(63.2)$ & $48(77.4)$ & $113(80.7)$ \\
\hline Follow-up visit & $140(63.3)$ & $10(52.6)$ & $41(66.1)$ & 89 (63.6) \\
\hline Did not apply during the weeks before the baseline and the follow-up visit & $48(21.7)$ & $7(36.8)$ & $14(22.6)$ & $27(19.3)$ \\
\hline
\end{tabular}

*Costa Rica poverty line in 2016: 95761 Costa Rican colón. ${ }^{37}$

(1) all study participants who applied pesticides during the 12 months prior to the baseline or the follow-up visit $(n=221)$ and (2) participants who applied pesticides during the week prior to one or both study visits $(n=190$; see online supplementary figure S2). For both data sets, we used naïve mixed-effect models with individual worker as the only random factor to estimate within-worker and between-worker variability in weekly pesticide exposure scores (EXPOSURE ${ }^{\text {WEEK }}$ ), intraclass correlation coefficient, and $\mathrm{R}_{0.95}$ (ratio of the 97.5 th and 2.5th percentile of the between-worker and within-worker exposure intensity scores distributions). We also ran mixed-effect models to identify the main predictors (eg, farm type, training on pesticide use and farm ownership) of weekly exposure intensity scores (EXPO$S U R E^{\text {WEEK }}$ ) using the two data sets separately. We included potential predictors in our multivariate models if their $p$ value in the bivariate mixed model was $<0.20$. We used ln-transformed weekly exposure intensity scores in all models $(x+1)$ as the data were not normally distributed. Statistical analyses were done using STATA V.15.0.

This manuscript has been developed according to the Consolidated Standards of Reporting Trials (see flow chart in online supplementary figure S2) and the Strengthening the Reporting of Observational Studies in Epidemiology.

\section{RESULTS}

\section{Demographic characteristics}

Most of the 221 pesticide applicators were male (99\%), born in Costa Rica (61\%), had a low educational level (sixth grade or under; 69\%) and were employed as farm workers $(57 \%)$ (table 3). About a third of applicators were aged above 40 years (39\%); another third lived below the Costa Rican poverty line (30\%). Most participants worked on conventional farms (60\%), followed by sustainable farms (27\%) and organic farms (13\%). The reported use of the 15 different active ingredients in the year before the follow-up visit can be found in online supplementary table S1.

\section{Pesticide use practices}

Only half of the applicators reported having received some training on pesticide use (50\%) (table 3). Applicators had used pesticides for a median of 16.0 years (IQR: 7-31; table 4). Relatively few workers reported having used gloves, goggles, mask with carbon filter or dust masks $(<14 \%)$. For all PPE, except boots, a discrepancy was observed between reported PPE ownership and frequency of use (see online supplementary figure S3). About $78 \%$ and $63 \%$ of the workers reported applying pesticides during the week prior to the baseline and follow-up visits, respectively. On average, they applied pesticides for 4.0 hours (IQR: 1.0-9.0) during the week prior to the baseline visit and for 2.0 hours (IQR: 0-9.0) during the week prior to follow-up visit. Finally, $22 \%$ of the applicators did not use pesticides during the weeks prior to the study visits, with higher percentages in organic farms (37\%) than in sustainable and conventional farms (23\% and 19\%, respectively).

\section{Pesticide exposure intensity scores}

Overall, applicators had median EXPOSURE ${ }^{\text {WEEK }}$ scores at the baseline and follow-up visits of 26.8 (IQR: 5.5-58.1) and 10.8 
Table 4 Description of pesticide applicators' exposure characteristics in Zarcero County, Costa Rica, 2016

\begin{tabular}{|c|c|c|c|c|c|c|c|c|c|}
\hline & Visit \% & Possible scores & $\mathrm{n}$ & Minimum & p25 & p50 & p75 & Maximum & $r_{s}$ \\
\hline Years worked with pesticides & n.a. & n.a. & 221 & 0.00 & 7.00 & 16.00 & 31.00 & 67.00 & n.a. \\
\hline \multirow[t]{2}{*}{ Number of different pesticides used in week prior to study visit } & B & n.a. & 221 & 0.00 & 0.00 & 2.00 & 4.00 & 11.00 & 0.65 \\
\hline & $\mathrm{F}$ & n.a. & 221 & 0.00 & 0.00 & 1.00 & 4.00 & 9.00 & $0.70^{*}$ \\
\hline \multirow[t]{2}{*}{ Number of days since last spraying } & B & n.a. & 208 & 0.00 & 0.00 & 2.00 & 4.50 & 166.00 & 0.29 \\
\hline & $\mathrm{F}$ & n.a. & 204 & 0.00 & 0.00 & 2.00 & 8.00 & 210.00 & $0.07^{*}$ \\
\hline \multirow[t]{2}{*}{ Application hours in week prior to study visit } & B & n.a. & 221 & 0.00 & 1.00 & 4.00 & 9.00 & 48.00 & 0.46 \\
\hline & $\mathrm{F}$ & n.a. & 221 & 0.00 & 0.00 & 2.00 & 6.00 & 48.00 & $0.54^{*}$ \\
\hline \multirow[t]{2}{*}{$P P E^{\mathrm{EYE}}$} & B & 1 to 0.01 & 221 & 0.01 & 0.08 & 0.10 & 0.10 & 0.10 & \\
\hline & $\mathrm{F}$ & & 140 & 0.01 & 0.10 & 0.10 & 0.10 & 0.10 & $0.52^{*}$ \\
\hline \multirow[t]{2}{*}{$P P E^{\text {HAND }}$} & B & 1 to 0.08 & 221 & 0.08 & 0.24 & 0.40 & 0.40 & 0.40 & \\
\hline & $\mathrm{F}$ & & 140 & 0.08 & 0.36 & 0.40 & 0.40 & 0.40 & $0.64^{*}$ \\
\hline \multirow[t]{2}{*}{$P P E^{\mathrm{FEET}}$} & B & 1 to 0.01 & 221 & 0.01 & 0.01 & 0.01 & 0.01 & 0.10 & \\
\hline & $\mathrm{F}$ & & 140 & 0.01 & 0.01 & 0.01 & 0.01 & 0.01 & 0.98 * \\
\hline \multirow[t]{2}{*}{$P P E^{\mathrm{MOUTH}}$} & B & 1 to 0.01 & 221 & 0.01 & 0.06 & 0.08 & 0.10 & 0.10 & \\
\hline & $\mathrm{F}$ & & 140 & 0.01 & 0.03 & 0.10 & 0.10 & 0.10 & $0.55^{*}$ \\
\hline \multirow[t]{2}{*}{$P P E^{\text {UP-BODY }}$} & B & 1 or 0.02 & 221 & 0.02 & 0.02 & 0.06 & 0.11 & 0.20 & \\
\hline & $\mathrm{F}$ & & 140 & 0.02 & 0.04 & 0.06 & 0.11 & 0.20 & $0.49^{*}$ \\
\hline \multirow[t]{2}{*}{$P P E^{\mathrm{LEG}}$} & B & 1 to 0.01 & 221 & 0.01 & 0.01 & 0.03 & 0.03 & 0.10 & \\
\hline & $\mathrm{F}$ & & 140 & 0.01 & 0.01 & 0.03 & 0.03 & 0.10 & $0.40^{*}$ \\
\hline \multirow[t]{2}{*}{$P P E$} & B & 1 to 0.14 & 221 & 0.14 & 0.48 & 0.64 & 0.70 & 1.00 & \\
\hline & $\mathrm{F}$ & & 140 & 0.13 & 0.43 & 0.58 & 0.65 & 0.78 & 0.71 * \\
\hline SHOWER & B & 1 to 0.7 & 221 & 0.70 & 0.80 & 0.80 & 0.90 & 1.00 & n.a. \\
\hline CHANGE & B & 1 to 0.7 & 221 & 0.70 & 0.80 & 0.80 & 0.90 & 1.00 & n.a. \\
\hline \multirow[t]{2}{*}{ EXPOSURE ${ }^{\text {INTENSITY }}$} & B & 13 to 0.89 & 221 & 1.04 & 4.44 & 6.65 & 9.33 & 14.58 & \\
\hline & & & 140 & 0.63 & 3.30 & 4.68 & 6.16 & 8.16 & $0.83^{*}$ \\
\hline \multirow[t]{2}{*}{ EXPOSURE ${ }^{\text {WEEK }}$} & B & n.a. & 221 & 0.00 & 5.53 & 26.73 & 58.06 & 311.04 & 0.46 \\
\hline & $\mathrm{F}$ & n.a. & 221 & 0.00 & 0.00 & 10.83 & 34.10 & 419.90 & $0.56^{*}$ \\
\hline
\end{tabular}

Follow-up scores only estimated for applicators who applied pesticides in the week before the visit.

Applicators who did not apply in the week before the baseline or follow-up visit were set to 0 .

$r_{s^{\prime}}$ Pearson rank correlation coefficients for baseline and follow-up visit estimates.

p25, p50, p75: percentiles

${ }^{*}$ Analysis done for the 122 applicators who applied pesticides at the baseline and follow-up visit.

B, baseline visit; F, follow-up visit; n.a., not applicable; PPE, personal protective equipment.

(IQR: 0-19.9) hours, respectively (table 4). At baseline, the median EXPOSURE ${ }^{I N T E N S I T Y}$ score was 6.7 (IQR: 4.4-9.3), and the hygienic behaviours after pesticides application showed a median protective effect of 0.6 (IQR: 0.6-0.8) for both showering and changing clothes. The multiplicative protective effect of PPE use (PPE) over the six body parts reduced exposure to pesticides by a median score of 0.6 (IQR: 0.5-0.7). Hardly any PPE was used for $P P E^{H A N D}, P P E^{M O U T H}$ and $P P E^{E Y E}$, but hands $\left(P P E^{H A N D}\right)$ contributed the most to the overall exposure (median 0.4, IQR: 0.2-0.4; table 4 and see online supplementary figure S3).

\section{Correlation of pesticide exposure variables and scores between study visits}

'Hours of pesticide sprayed last week' and EXPOSURE WEEK were moderately correlated between study visits (both $r_{s}=0.46$; $\mathrm{n}=221$; table 4), whereas PPE and EXPOSURE INTENSITY were strongly correlated $\left(r_{s}=0.71\right.$ and $r_{s}=83$, respectively; $\left.n=122\right)$. Individual weighted PPE scores were moderately to strongly correlated between visits $\left(r_{s}=0.40-0.98 ; n=122\right)$.

\section{Variability of EXPOSURE ${ }^{\text {WEEK }}$ scores}

Between-worker EXPOSURE ${ }^{\text {WEEK }}$ variability (39\%) was slightly smaller than within-worker variability among all study participants (61\%) (model A; table 5). However, the opposite was found among study participants who had applied pesticides during the
1 week prior to one or both study visits $(53 \%$ and 47\%, respectively; table 5). When we included all predictors in our multivariate models, only $6 \%$ of the variability in weekly exposure scores was explained. Notably, in the model that excluded the 31 workers who did not apply pesticides during the weeks prior to both study visits, $39 \%$ of the variability in weekly exposure intensity scores was explained.

\section{Predictors of EXPOSURE ${ }^{\text {WEEK }}$ scores}

Farm type (organic, sustainable and conventional), training in pesticide use (yes vs no), years working with pesticides (years) and country of birth (Nicaragua vs Costa Rica) were associated with EXPOSURE ${ }^{\text {WEEK }}$ scores in the bivariate analyses and were therefore included in the multivariate mixed-effects models (for the full list, see online supplementary table S4).

In the multivariate analysis of all workers who reported applying pesticides during the 12 months prior to the baseline visit, we found significantly lower weekly exposure scores for workers who had received training on pesticide use compared with workers without such training $(\exp (ß)=0.67,95 \%$ CI 0.45 to 0.99 ; table 5 ). As expected, given that less synthetic pesticides were used in organic farms, weekly exposure intensity scores for workers from conventional and sustainable farms were higher than those of workers from organic farms $(\exp (ß)=2.15,95 \%$ 
Table 5 Naïve and multivariate mixed-effect regression models for weekly pesticide exposure in Zarcero County, Costa Rica, 2016

\begin{tabular}{|c|c|c|c|c|c|c|c|c|c|c|c|}
\hline $\begin{array}{l}\text { Model } A \\
\text { EXPOSURE WEEK } \\
\text { All farmers }(\mathrm{n}=442 ; \\
\mathrm{co}=280, \mathrm{su}=124, \text { or }=38)^{*}\end{array}$ & $\begin{array}{l}\text { Variance } \\
\text { component }\end{array}$ & $\%$ & GSD & $\mathrm{R}_{0.95}{ }^{\dagger}$ & ICC & $\begin{array}{l}\text { Model B } \\
\text { EXPOSURE }{ }^{\text {WEEK }} \neq \\
>0(\mathrm{n}=312 ; \mathrm{co}=202, \\
\mathrm{su}=89, \text { or }=21)^{*}\end{array}$ & $\begin{array}{l}\text { Variance } \\
\text { component }\end{array}$ & $\%$ & GSD & $\mathrm{R}_{0.95}{ }^{\dagger}$ & ICC \\
\hline Empty model & & & & & & Empty model & & & & & \\
\hline Random effect intercept & 1.16 & 0.39 & 2.93 & 67.79 & 0.39 & Random effect intercept & 0.74 & 0.53 & 2.36 & 29.13 & 0.53 \\
\hline Random error & 1.79 & 0.61 & 3.81 & 188.73 & & Random error & 0.66 & 0.47 & 2.25 & 24.18 & \\
\hline Multivariate model & & & & & & Multivariate model & & & & & \\
\hline Random effect intercept & 1.03 & 0.37 & 2.76 & 53.74 & 0.37 & Random effect intercept & 0.48 & 0.56 & 2.00 & 15.12 & 0.56 \\
\hline Random error & 1.75 & 0.63 & 3.75 & 178.16 & & Random error & 0.38 & 0.44 & 1.85 & 11.13 & \\
\hline Full model explains & & \multicolumn{3}{|c|}{$\begin{array}{l}6 \% \\
\text { of variability }\end{array}$} & & Full model explains & & \multicolumn{3}{|c|}{$\begin{array}{l}39 \% \\
\text { of variability }\end{array}$} & \\
\hline Predictor & & $\exp (B)$ & \multicolumn{2}{|c|}{$\exp (B)(95 \% \mathrm{Cl})$} & $P$ value & Predictor & & $\exp (\beta)$ & \multicolumn{2}{|c|}{$\exp (B)(95 \% \mathrm{Cl})$} & $P$ value \\
\hline Intercept & & 6.40 & 3.41 & 16.05 & $<0.01$ & Intercept & & 27.25 & 16.24 & 49.12 & $<0.01$ \\
\hline \multirow[t]{3}{*}{ Farm type } & Organic & 1.00 & 1.00 & 1.00 & & Farm type & Organic & 1.00 & 1.00 & 1.00 & \\
\hline & Sustainable & 1.61 & 0.77 & 3.32 & 0.23 & & Sustainable & 1.00 & 0.60 & 1.68 & 0.99 \\
\hline & Conventional & 2.15 & 1.09 & 4.23 & 0.03 & & Conventional & 1.36 & 0.84 & 2.20 & 0.21 \\
\hline Years worked with pesticides & & 0.99 & 0.98 & 1.01 & 0.29 & $\begin{array}{l}\text { Years worked with } \\
\text { pesticides }\end{array}$ & & 0.99 & 0.98 & 1.00 & 0.26 \\
\hline \multirow[t]{2}{*}{ Training } & No & 1.00 & 1.00 & 1.00 & & Training & No & 1.00 & 1.00 & 1.00 & \\
\hline & Yes & 0.67 & 0.45 & 0.99 & 0.04 & & Yes & 0.62 & 0.48 & 0.81 & $<0.01$ \\
\hline \multirow[t]{2}{*}{ Nationality } & Costa Rica & 1.00 & 1.00 & 1.00 & & Nationality & Costa Rica & 1.00 & 1.00 & 1.00 & \\
\hline & Nicaragua & 1.14 & 0.74 & 1.77 & 0.55 & & Nicaragua & 1.12 & 0.84 & 1.50 & 0.43 \\
\hline
\end{tabular}

Model A: all study participants who applied pesticides during the last 12 months before the baseline visit (221 farm workers, 442 observations).

Model B: study participants who applied pesticides during the week before the baseline and/or follow-up visits (190 farm workers, 312 observations.

${ }^{*} \mathrm{co}$, conventional; or, organic; su, sustainable.

tIn transformed values.

$\$ 130$ observations were 0 as participants did not apply pesticides in the week before the baseline or follow-up visit.

GSD, geometric SD;ICC, intraclass correlation coefficient; $\mathrm{R}_{0.95}$ r ratio of the 97.5 th and 2.5 th percentile of the intraindividual and interindividual exposure distribution.

CI 1.09 to 4.23 ; $\exp (ß)=1.61,95 \%$ CI 0.77 to 3.32 , respectively). We did not find differences in weekly exposure scores by years working with pesticides nor by country of birth.

Among the subset of workers who reported applying pesticides during the week prior to the baseline visit and/or prior to the follow-up visit, the difference in exposure scores between workers with and without training on safe pesticide use was negligible $(\exp (ß)=0.62,95 \%$ CI 0.48 to 0.81 ; table 5$)$. Notably, we no longer found differences in exposure scores between workers from conventional, sustainable and organic farms $(\exp (ß)=1.36$, $95 \%$ CI 0.84 to 2.20 ; and $\exp (\beta)=1.00,95 \%$ CI 0.60 to 1.68 , respectively). Associations of years working with pesticides and country of birth with EXPOSURE ${ }^{\text {WEEK }}$ scores did not change.

\section{DISCUSSION}

We estimated weekly pesticide exposure scores for applicators from organic, sustainable and conventional smallholder farms in Costa Rica, using an adapted questionnaire-based exposure algorithm. Compared with previously used algorithms, ${ }^{37}$ our modified algorithm had a stronger focus on PPE use in order to better fit the context of pesticide application in LMICs. In our study, we found high within-worker and between-worker variability of weekly pesticide exposure intensity scores. This variability was mainly driven by differences in pesticide application hours between study visits. The hours of pesticide application may have varied throughout the 4 months of our study fieldwork due to differences in pests, weather conditions (eg, rain, wind) and farming practices (eg, pesticides should not be sprayed within a certain time window before harvest). ${ }^{18} 26$ Nevertheless, correlation of PPE use between study visits was moderate, which could be due to differences in pesticides used, availability of PPE or discomfort of wearing PPE all the time. ${ }^{33}$ Moreover, we observed a considerable lack of protection of hands (gloves), eyes (glasses) and airways (dust masks or respirators), which may lead to higher pesticide exposures via these pathways.

In our study, workers who had received training on safe pesticide handling practices had exposure scores that were three times lower than those of workers who had not received training. This difference has also been observed in another study in LMICs. ${ }^{33} 34$ However, to our knowledge, none of these studies used a (semi) quantitative assessment of the impact of training in reducing pesticide exposure scores; they have only used measures such as increase in PPE use or adherence to appropriate hygiene practices at work. In the present study, we observed that applicators from conventional farms had higher weekly pesticide exposure scores than those from organic farms. Higher scores in conventional applicators are of special concern as they also sprayed more hazardous pesticide products than the applicators from sustainable and organic farms. ${ }^{17}$ However, when comparing only applicators who applied pesticides in the week prior to the visits, the differences in exposure between the farming systems disappeared; this finding may be due to the small sample size of the organic farmers spraying in the week prior to the visits $(n=10)$, resulting in reduced statistical power.

Our study has several shortcomings. First, all data on pesticide use were self-reported because workers in the study area did not keep records on historical pesticide or PPE use. Second, instead of assessing the amount of pesticide applied like other studies in LMICs have done, ${ }^{7}$ we collected information on the number of hours of pesticide application, mainly because applicators did not always know how the pesticides had been prepared (eg, farm owners would mix the pesticide with water and later give the mix 
to the applicator). Third, we did not collect data on important pesticide exposure routes such as contact with sprayed crops or soil when re-entering the field after an application, packing crops, drift from neighbouring fields, use of agricultural pesticides at home, or consumption of potentially contaminated crops or water, which could also occur in these settings. 3536 Fourth, we could not compare our model estimates with those from previous questionnaire-based exposure algorithms. ${ }^{57}$ In the present study, we looked at average exposure over a week, whereas the Agricultural Health Study focused on the application of specific active ingredients (eg, assessing whether gloves were used when ingredient $\mathrm{XY}$ was applied). ${ }^{5}$ Moreover, the Ethiopian study used a binary variable for PPE use (eg, do you use gloves for pesticide spraying? yes or no) and also took into account the amount of pesticide used (in kilogram per application, as it was recorded by farm owners). ${ }^{7}$ Fifth, the high variability in frequency of application (hours) and the number of different pesticide products (up to 11 different products were sprayed by a single applicator over 1 week) between weeks made it difficult for us to assess long-term exposure to specific active ingredients. Lastly, in our study, we assessed the applicants only at two time points during the application season, and hence we did not get a fully representative picture of the pesticide spraying activities $(22 \%$ of the participants did not apply in the weeks when the study was conducted). Further research should collect exposure information at more than two time points and also determine the feasibility of implementing a reporting system for specific active ingredients used over time.

Our adapted pesticide exposure algorithm has two main strengths in comparison with previous questionnaire-based exposure algorithms. ${ }^{37}$ First, we focused on fewer but contextrelevant exposure variables such as mixing of pesticides, PPE use, changing cloths and showering after an application. Second, we took into account more detailed information on PPE use over time. More specifically, we adapted our PPE assessment to a weighing scheme previously used in observational assessments (eg, DREAM) that focused on protected body areas and quality of PPE ${ }^{4}$ and we also estimated the average time during which PPE was used (eg, from always to rarely).

\section{CONCLUSION}

In this study of applicators from smallholder farms in Costa Rica, we determined the importance of collecting self-reported data on pesticide use repeatedly due to its high temporal variability (day-to-day within worker) and absence of application records. Further research on occupational pesticide use should collect exposure information at several time points to capture variability in weekly pesticide exposure intensity scores and should determine the feasibility of implementing a reporting system for specific active ingredients used over time. Hence, our questionnaire-based exposure algorithm could allow the calculation of semiquantitative estimates of average pesticide exposure for applicators from LMICs in an affordable and logistically feasible way. Estimated weekly pesticide exposure intensity scores could be potentially used to examine the associations of pesticide exposure with acute and chronic health outcomes. Application in intervention studies to investigate the effect of training on safe pesticide use could be another promising option.

\section{Author affiliations}

${ }^{1}$ Institute for Risk Assessment Sciences, Utrecht University, Utrecht, The Netherlands ${ }^{2}$ Department Environmental Chemistry, Swiss Federal Institute of Aquatic Science and Technology (Eawag), Duebendorf, Switzerland

${ }^{3}$ Institute of Biogeochemistry and Pollutant Dynamics, ETH Zürich, Zurich, Switzerland
${ }^{4}$ Swiss Tropical and Public Health Institute (Swiss TPH), Basel, Basel-Stadt, Switzerland

${ }^{5}$ University of Basel, Basel, Switzerland

${ }^{6}$ Division of Occupational and Environmental Medicine, Lund University, Lund, Sweden

${ }^{7}$ Central American Institute for Studies on Toxic Substances, Universidad Nacional, Heredia, Costa Rica

${ }^{8}$ Center for Environmental Research and Children's Health (CERCH), School of Public Health, University of California, Berkeley, California, USA

Acknowledgements We gratefully acknowledge the study participants and staff (A Alfaro, A Campos, S Colombari, C Hyland, M Quirós-Lépiz, G Rodríguez, A Ulloa, $\mathrm{H}$ Wey). We also thank Christian Stamm for his valuable comments to the final draft. Finally, we thank the whole PESTROP team for their contribution along the fieldwork and valuable discussions around the manuscript.

Contributors SF, AMM, PS, CL, HK, MSW: conception and planning. SF, PS, AMM: collection of data. SF, AMM, BvWdJ, HK: analysis and interpretation of data. All authors participated in drafting and final approval of the manuscript.

Funding This work was supported by the Swiss Federal Institute of Aquatic Science and Technology (EAWAG), Universidad Nacional in Costa Rica, Forschungsfonds of the University of Basel, and the Swiss Network for International Studies (SNIS). SF's effort was also supported by a fellowship from the Swiss National Science Foundation (SNSF)

Competing interests None declared.

\section{Patient consent for publication Not required.}

Ethics approval All study materials and procedures were approved by the human subjects committee of the Universidad Nacional in Costa Rica (UNA-CECUNAACUE-04-2016) and the Ethical Board of Ethikkommission Nordwest- und Zentralschweiz in Switzerland (EKNZ-UBE 2016-00771). Written informed consent was obtained from all study participants at enrolment.

Provenance and peer review Not commissioned; externally peer reviewed. Data availability statement Data are available upon reasonable request.

Open access This is an open access article distributed in accordance with the Creative Commons Attribution Non Commercial (CC BY-NC 4.0) license, which permits others to distribute, remix, adapt, build upon this work non-commercially, and license their derivative works on different terms, provided the original work is properly cited, appropriate credit is given, any changes made indicated, and the use is non-commercial. See: http://creativecommons.org/licenses/by-nc/4.0/.

\section{ORCID iDs}

Samuel Fuhrimann http://orcid.org/0000-0002-1861-1737

Philipp Staudacher https://orcid.org/0000-0001-8314-1519

Christian Lindh https://orcid.org/0000-0001-7435-9890

Berna van Wendel de Joode https://orcid.org/0000-0001-9699-5046

Ana M Mora https://orcid.org/0000-0002-2008-9714

Mirko S Winkler https://orcid.org/0000-0001-7387-3863

Hans Kromhout https://orcid.org/0000-0002-4233-1890

\section{REFERENCES}

1 Christensen K, Christensen CH, Wright JM, et al. The use of epidemiology in risk assessment: challenges and opportunities. Human and Ecological Risk Assessment: An International Journal 2015;21:1644-63.

2 Blair A, Ritz B, Wesseling C, et al. Pesticides and human health. Occup Environ Med 2015;72:81-2.

3 Dosemeci M, Alavanja MCR, Rowland AS, et al. A quantitative approach for estimating exposure to pesticides in the agricultural health study. Ann Occup Hyg 2002:46:245-60.

4 Van-Wendel-de-Joode B, Brouwer DH, Vermeulen R, et al. Dream: a method for semiquantitative dermal exposure assessment. Ann Occup Hyg 2003;47:71-87.

5 Coble J, Thomas KW, Hines CJ, et al. An updated algorithm for estimation of pesticide exposure intensity in the agricultural health study. Int J Environ Res Public Health 2011;8:4608-22

6 Thomas KW, Dosemeci M, Coble JB, et al. Assessment of a pesticide exposure intensity algorithm in the agricultural health study. J Expo Sci Environ Epidemiol 2010;20:559-69.

7 Negatu B, Vermeulen R, Mekonnen Y, et al. A method for semi-quantitative assessment of exposure to pesticides of applicators and re-entry workers: an application in three farming systems in Ethiopia. ANNHYG 2016;60:669-83.

8 Lesmes-Fabian C, García-Santos G, Leuenberger F, et al. Dermal exposure assessment of pesticide use: the case of sprayers in potato farms in the Colombian highlands. Sci Total Environ 2012;430:202-8

9 Blanco LE, Aragón A, Lundberg I, et al. The determinants of dermal exposure ranking method (DERM): a pesticide exposure assessment approach for developing countries. Ann Occup Hyg 2008;52:535-44. 
10 Kamel F, Engel LS, Gladen BC, et al. Neurologic symptoms in licensed pesticide applicators in the agricultural health study. Hum Exp Toxicol 2007;26:243-50.

11 Negatu B, Vermeulen R, Mekonnen Y, et al. Neurobehavioural symptoms and acute pesticide poisoning: a cross-sectional study among male pesticide applicators selected from three commercial farming systems in Ethiopia. Occup Environ Med 2018;75:283-9.

12 Montgomery MP, Kamel F, Saldana TM, et al. Incident diabetes and pesticide exposure among licensed pesticide applicators: agricultural health study, 1993-2003. Am J Epidemiol 2008;167:1235-46.

13 Slager RE, Poole JA, LeVan TD, et al. Rhinitis associated with pesticide exposure among commercial pesticide applicators in the agricultural health study. Occup Environ Med 2009;66:718-24.

14 Negatu B, Kromhout H, Mekonnen Y, et al. Occupational pesticide exposure and respiratory health: a large-scale cross-sectional study in three commercial farming systems in Ethiopia. Thorax 2017;72:498.1-9.

15 De Roos AJ, Blair A, Rusiecki JA, et al. Cancer incidence among glyphosate-exposed pesticide applicators in the agricultural health study. Environ Health Perspect 2005;113:49-54.

16 Monge P, Partanen T, Wesseling C, et al. Assessment of pesticide exposure in the agricultural population of Costa Rica. Ann Occup Hyg 2005;49:375-84.

17 Staudacher P, Winkler MS, Mora AM, et al. Knowledge, attitude and practice of pesticide use in organic and conventional farming in smallholder farming in Uganda and Costa Rica. Environ Res.

18 Ramirez-Munoz F, Bravo-Duran V, Herrera-Ledezma G. Use of the herbicide glyphosate in Costa Rica between 2007-2015. Uniciencia 2017;31:59-72.

19 Barraza D, Jansen $K$, van Wendel de Joode $B$, et al. Pesticide use in banana and plantain production and risk perception among local actors in Talamanca, Costa Rica. Environ Res 2011;111:708-17.

20 Hanchenlaksh C, Povey A, O'Brien S, et al. Urinary DAP metabolite levels in Thai farmers and their families and exposure to pesticides from agricultural pesticide spraying. Occup Environ Med 2011;68:625-7.

21 Baharuddin MRB, Sahid IB, Noor MABM, et al. Pesticide risk assessment: a study on inhalation and dermal exposure to 2,4-D and paraquat among Malaysian paddy farmers. Journal of Environmental Science and Health, Part $B$ 2011;46:600-7.

22 Lesmes-Fabian C, Fabian CL, Binder CR. Dermal exposure assessment to pesticides in farming systems in developing countries: comparison of models. Int J Environ Res Public Health 2015;12:4670-96.

23 FAO. Smallholders and family farmers, 2012. Available: http://www.fao.org/fileadmin/ templates/nr/sustainability_pathways/docs/Factsheet_SMALLHOLDERS.pdf [Accessed 22 Mar 2019].
24 London L, Myers JE. Use of a crop and job specific exposure matrix for retrospective assessment of long-term exposure in studies of chronic neurotoxic effects of agrichemicals. Occup Environ Med 1998;55:194-201.

25 Chetty-Mhlanga S, Basera W, Fuhrimann S, et al. A prospective cohort study of schoolgoing children investigating reproductive and neurobehavioral health effects due to environmental pesticide exposure in the Western Cape, South Africa: study protocol BMC Public Health 2018;18:857.

26 Hoppin JA. Integrating exposure measurements into epidemiologic studies in agriculture. Scand J Work Environ Health 2005;31 Suppl 1:115-7.

27 Godfray HCJ, Beddington JR, Crute IR, et al. Food security: the challenge of feeding 9 billion people. Science 2010;327:812-8.

28 Rother H-A. Pesticide labels: Protecting liability or health? - Unpacking "misuse" of pesticides. Current Opinion in Environmental Science \& Health 2018;4:10-15.

29 Fuhrimann S, Winkler MS, Staudacher $\mathrm{P}$, et al. Exposure to pesticides and health effects on farm owners and workers from conventional and organic agricultural farms in Costa Rica: protocol for a cross-sectional study. JMIR Res Protoc 2019;8:e10914-13.

30 INEC. Proyecto VI Censo Nacional Agropecuario 2014. San José: Instituto Nacional de Estadística y Censos (INEC), 2015. http://www.inec.go.cr/sites/default/ files/documentos/agropecuario/metodologias/documentos_metodologicos/ meagropeccenagro2014-001.pdf

31 Baker JM, Rojas-Valverde D, Gutiérrez R, et al. Portable functional neuroimaging as an environmental epidemiology tool: a how-to guide for the use of fNIRS in field studies. Environ Health Perspect 2017;125:094502.

32 Barr DB. Biomonitoring of exposure to pesticides. Journal of Chemical Health and Safety 2008;15:20-9.

33 Keifer MC. Effectiveness of interventions in reducing pesticide overexposure and poisonings. Am J Prev Med 2000;18:80-9.

34 Naidoo S, London L, Rother $\mathrm{H}-\mathrm{A}$, et al. Pesticide safety training and practices in women working in small-scale agriculture in South Africa. Occup Environ Med 2010;67:823-8.

35 van Wendel de Joode B, Mergler D, Wesseling C, et al. Manual de pruebas neuroconductuales. published online first, 2000. Available: http://bases.bireme.br/ cgi-bin/wxislind.exe/iah/online/?IsisScript=iah/iah.xis\&src=google\&base=REPIDISCA\& lang=p\&nextAction=Ink\&exprSearch=4068\&indexSearch=ID [Accessed $20 \mathrm{Nov}$ 2015].

36 van Wendel de Joode B, Barraza D, Ruepert C, et al. Indigenous children living nearby plantations with chlorpyrifos-treated bags have elevated 3,5,6-trichloro-2-pyridinol (TCPy) urinary concentrations. Environ Res 2012;117:17-26.

37 INEC. Compendio de indicadores sociales: límites de pobreza por zona. Compend. indicadores Soc. - Límites Pobr, 2016. Available: https://www.estadonacion.or.cr/ estadisticas-index\#social [Accessed 2 Apr 2019]. 